\title{
Laboratory Performance of Developed Centrifugal Blower of Aero Blast Sprayer for High Density Plantation Mango Orchard
}

\author{
B. B. Badgire*, S. M. Mathur, R. K. Rathod and G. S. Tiwari \\ Department of Farm machinery and power Engineering, CTAE, MPUAT, \\ Udaipur-313001, Rajasthan, India \\ *Corresponding author
}

Keywords

HTP, HDP,

Centrifugal blower, Air volume

Article Info

Accepted:

15 December 2019

Available Online:

20January 2020

\section{A B S T R A C T}

\section{Introduction}

In India, horticulture has gained commercial tone in recent years and is an important component of Indian agriculture, having very significant share in the economy of the country. India has the advantage of diverse agro-climatic conditions that enables it to produce a wide range of horticultural crops round the year. The horticulture crops also provide better alternative for diversification of
Indian agriculture in view of higher return.

The projected growth in the world's population to nine billion by 2050 adds an extra challenge for food security (Anon., 2013). With the ever growing population and having limited land, water and labor resources and increase in the difference between food demand and supply, agricultural production has to be increased. Precise application of agriculture input like seed, fertilizer, water and pesticide is need of the day to increase the 
yield and productivity in field crops and horticultural crops.

The continuing decline in the availability of cultivable land, rising energy and land cost together with the mounting demand for horticultural produce, have given thrust to the concept of high density planting ( HDP ) of horticultural crops (Reddy, 2004).

Centrifugal blower discharges air at high velocity and low volume, which affects atomization, carry, penetration and coverage (Pompe \& Holterman, 1992). It also discharges air at high velocity with low volume which increases carry distance of spray \& penetration through canopy to reach tree canopy and hit the target effectively. The high velocity air stream produce better atomization and effective leaf coverage from both sides due to more air turbulence. To achieve effective spraying, air assisted sprayer is needed to operate correctly. The blower output must be in accordance with weather and crop characteristics.

The performance evaluation of developed centrifugal blower in lab will help to finalize operating parameter for effective application of pesticide in high density mango orchard with minimum losses and environmental pollution.

\section{Materials and Methods}

\section{Tree parameters measurement}

Fox et al., (2008) revealed that for best possible results, sprayer air velocity, volume and drop spectra should match to tree size, shape and density of canopy. In air carrier sprayer, spray liquid is conveyed to the target by air. The volume of air required is equal to the volume of the tree for effective coverage. The original air present in the canopy volume should be replaced by spray laden air generated by air assisted sprayer.

Mango trees have different shape and size. The information regarding canopy size, canopy height, leaf area, leaf density and canopy volume is required to estimate the air volume and spray volume application on mango tree. The data was collected for kesar mango variety with 9 years of age for 25 matured trees, from high density mango orchard research farm of American Spring \& Pressing Works Private Limited popularly known as 'ASPEE' Agricultural Research and Development Foundation, Malad (W), Mumbai-400064 located at Tanasa Ta. Wada Dist. Palghar near Thane (Maharashtra). The observation of overall canopy height above ground level, height to the point of maximum canopy diameter, height from ground to canopy skirt, canopy diameter parallel to the row were recorded (Fig.1). These tree parameters were measured with clinometer height gauge and a measuring tape.

\section{Estimation of Air volume required for spraying HDP mango orchard}

The theoretical air volume $\left(\mathrm{m}^{3} / \mathrm{s}\right)$ required for HDP mango orchard was calculated as follows (Joseph, 1990).

Air volume $\left(\mathrm{m}^{3} / \mathrm{s}\right)=\frac{\text { Speed }\left(\frac{\mathrm{m}}{\mathrm{h}}\right) \times \text { Spray width }(\mathrm{m}) \times \operatorname{Tree} \text { height }(\mathrm{m}) \times 1000}{6.5 \times 3600}$

Following assumptions were made:

a) $18 \mathrm{hp}$ Tractor having operating speed of 2.5 $\mathrm{km} / \mathrm{h}$ for spraying operation.

b) Operating spray width one side only, this is half of the mean canopy diameter of the mango tree and measured as $2.052 \mathrm{~m}$

c) Factor of safety for dense canopy is 6.5 . (Joseph, 1990).

Considering these assumptions, the air volume is as follows: 
Air volume $\left(\mathrm{m}^{3} / \mathrm{s}\right)=\frac{2.5\left(\frac{\mathrm{km}}{\mathrm{h}}\right) \times 2.052(\mathrm{~m}) \times 4.66(\mathrm{~m}) \times 1000}{6.5 \times 3600}$

$=1.021=1.0$

Air volume $\left(\mathrm{m}^{3} / \mathrm{s}\right)=1.00 \mathrm{~m}^{3} / \mathrm{s}$

Therefore air volume of $1.0 \mathrm{~m}^{3} / \mathrm{s}$ required to spray one side of row of mango tree. To spray internal two sides of row of mango trees double air volume is required.

Air volume required for two internal sides of row $=2 \times 1=2 \mathrm{~m}^{3} / \mathrm{s}$

Considering the blower efficiency $80 \%$ (Wilson et al., 1962) for effective spraying, the air volume required is as follows

The air volume required $=2 / 0.8$

$$
=2.5 \mathrm{~m}^{3} / \mathrm{s}
$$

Therefore, the theoretical air volume required for efficient spraying in HDP mango orchard was $2.5 \mathrm{~m}^{3} / \mathrm{s}$.

\section{Centrifugal blower}

The centrifugal blower is power driven machine moving continuous mass of air. It consists of an impeller confined to rotate in spiral involute casing. A centrifugal blower with forward curved blade impeller was selected and developed for the required air velocity and volume to be used in aero blast sprayer for HDP mango trees. Centrifugal blower consists of impeller and casing as shown in (Fig.2,3,4 and 5).

The developed centrifugal blower was fabricated and details are as given in Table A,

\section{Experimental set-up for laboratory testing of centrifugal blower}

All the experiments were conducted following American Air Moving and Control
Association (AMCA) standard. A complete set up for testing the performance of the centrifugal blower has shown in (Fig. 6). It was essentially consisted of a blower assembly, a wind tunnel assembly, power transmission assembly and various measurement instruments.

Experimental plan for performance evaluation of centrifugal blower in the laboratory

\begin{tabular}{|c|c|c|c|c|}
\hline 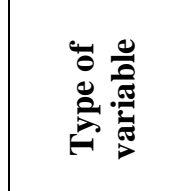 & 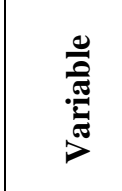 & 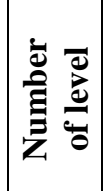 & 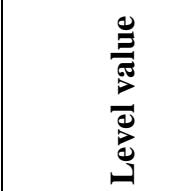 & 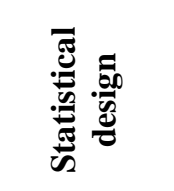 \\
\hline Independe & $\begin{array}{l}\text { Speed, } \\
\text { rpm }\end{array}$ & 04 & $\begin{array}{l}1800,2000, \\
2200,2400\end{array}$ & \\
\hline Dependent & \multicolumn{3}{|c|}{$\begin{array}{l}\text { Air velocity, } \mathrm{m} / \mathrm{s} \\
\text { Air discharge, } \mathrm{m}^{3} / \mathrm{s} \\
\text { Air pressure, } \mathrm{N} / \mathrm{m}^{2} \\
\text { Spray throw } \\
\text { Blower efficiency, \% } \\
\text { Power requirement }\end{array}$} & $\begin{array}{l}\text { CRD with } \\
\text { three } \\
\text { replications }\end{array}$ \\
\hline
\end{tabular}

The following procedure was implemented for evaluation of performance of centrifugal blower in the laboratory. The laboratory experiments were conducted as per AMCA standard.

1. Impeller was fitted in blower casing and the blower casing outlet was connected to wind tunnel assembly. The impeller was rotated in the clockwise or forward direction.

2. The proper combination of belt and 2 groove pulley selected to required blower speed as $1800 \mathrm{rpm}$.

3. Pitot tube was fixed with the help of screw provided at one point of the twenty traverse points and connected to the manometer.

4. Initially before starting the electric motor, the initial reading was recorded such as 
temperature and $\mathrm{RH}$ at the test location of the laboratory.

5. Electric motor was started and current was stabilized and reading were taken.

6. The dynamic head was measured at test section by connecting both end of pitot tube to the manometer. The static head at test section was measured by connecting static head section of Pitot tube to the manometer. Another dynamic head end was kept open to the atmosphere.

7. Current and voltage consumed by the electric motor was measured by ammeter and voltmeter and was recorded.

8. The procedure was repeated from step 3 to 7 for all traverse point of wind tunnel.

9. The procedure was repeated from 3 to 8 for other three speeds of blower.

10. Three replications were conducted for all above experiments.

\section{Results and Discussion}

During the study, air volume requirement for pesticide application on high density plantation mango tree was assessed. Based on the requirement a centrifugal blower for aero blast (air assisted) sprayer was designed and developed for $18 \mathrm{hp}$ tractor. The developed blower was tested in the laboratory to know the effect of speed (rpm) of operation.

\section{Physiological parameters of HDP mango trees}

Various tree parameters and canopy volume of 25 mango trees of $\mathrm{Cv}$. Kesar variety in HDP mango orchard are presented in table 1. The age of mango trees was 9 years. The canopy volume based on prolate spheroid formula and tree parameters were analyzed by statistical software. The minimum and maximum canopy volume was found to be $14.13 \mathrm{~m}^{3}$ and $30.67 \mathrm{~m}^{3}$ respectively. The mean canopy volume was $19.58 \mathrm{~m}^{3}$. The mean diameter parallel to the row, mean overall canopy height above ground level, mean height at maximum canopy diameter and mean height from ground to canopy skirt were found to be $4.10 \mathrm{~m}, 4.66 \mathrm{~m}, 2.67 \mathrm{~m}$ and 1.17 $\mathrm{m}$ respectively.

\section{Performance evaluation of centrifugal blower in laboratory}

Centrifugal blower was tested in the laboratory at four levels of speed adopting AMCA standard and procedure. The data collected were analyzed statistically and presented through table 5.4 to table 5.15. The performance curves are also presented through fig 5.1 to fig.5 .10. During the laboratory test temperature and relative humidity were measured and were found in the range $32^{\circ} \mathrm{C}-35^{\circ} \mathrm{C}$ and $36-40$ per cent respectively, three replications of the readings were taken.

\section{Effect of blower speed on air velocity and air discharge of the blower}

The developed centrifugal blower was run in the laboratory at four levels (1800, 2000, 2200, $2400 \mathrm{rpm}$ ) and data were collected for air velocity and air discharge and given in table 3 .

The data were analyzed statistically and ANOVA ( table 2 ) shows that blower speed had significant effect on air velocity and air discharge of the centrifugal blower at 1 and 5 per cent level of significance respectively. The relationship between air discharge with blower speed is shown in fig. 1. The curve shows that the air discharge increases with the increase in blower speed. Similar results were reported by Adachi et al., (2001) and Dhande (2014) for testing of centrifugal blower in the laboratory. 


\section{Table.A}

\begin{tabular}{|c|c|}
\hline Impeller & \\
\hline Type & : forward curved blade \\
\hline Inlet diameter & $: 340 \mathrm{~mm}$ \\
\hline Outlet diameter & $: 410 \mathrm{~mm}$ \\
\hline Width of impeller & $: 230 \mathrm{~mm}$ \\
\hline Material & : Stainless steel \\
\hline \multicolumn{2}{|l|}{ Blade } \\
\hline Inlet blade angle & $: 14^{0}$ \\
\hline Outlet blade angle & $: 160^{\circ}$ \\
\hline Width of blade & $: 35 \mathrm{~mm}$ \\
\hline Length of blade & : $115 \mathrm{~mm}$ (one side) x 2 \\
\hline Number of blades & : 40 ( single side) $\times 2$ \\
\hline Material & : Stainless steel \\
\hline \multicolumn{2}{|l|}{ Casing } \\
\hline Maximum diameter & $: 725 \mathrm{~mm}$ \\
\hline Minimum diameter & $: 635 \mathrm{~mm}$ \\
\hline Width of casing & $: 270 \mathrm{~mm}$ \\
\hline Outlet size & $: 210 \mathrm{~mm} \varnothing$ \\
\hline Casing inlet size & : 460mm $\varnothing$ and $280 \mathrm{~mm} \varnothing$ \\
\hline Material & : Fiber Reinforced plastic (FRP) \\
\hline
\end{tabular}


Table.1 Physiological parameters of high density plantation mango orchard of variety $\mathrm{Cv}$ Kesar and canopy volume

\begin{tabular}{|c|c|c|c|c|c|}
\hline Sample no. & $\mathbf{D}_{1}(\mathrm{~m})$ & $\mathbf{H}_{\mathbf{t}}(\mathbf{m})$ & $\mathbf{H}_{\mathrm{c}}(\mathbf{m})$ & $\mathrm{H}_{\mathrm{s}}(\mathrm{m})$ & $P S_{\mathrm{cv}}\left(\mathbf{m}^{3}\right)$ \\
\hline 1 & 3.60 & 4.46 & 2.60 & 1.00 & 14.22 \\
\hline 2 & 4.10 & 4.90 & 2.71 & 0.95 & 30.67 \\
\hline 3 & 3.57 & 4.57 & 2.65 & 1.10 & 14.36 \\
\hline 4 & 4.70 & 5.10 & 2.80 & 1.20 & 28.20 \\
\hline 5 & 3.65 & 4.56 & 2.45 & 1.15 & 16.02 \\
\hline 6 & 4.25 & 4.71 & 2.70 & 1.25 & 20.46 \\
\hline 7 & 4.10 & 4.31 & 2.65 & 1.10 & 16.16 \\
\hline 8 & 3.80 & 4.15 & 2.41 & 1.10 & 14.47 \\
\hline 9 & 3.90 & 4.20 & 2.50 & 1.20 & 14.84 \\
\hline 10 & 4.30 & 4.81 & 2.81 & 1.31 & 20.86 \\
\hline 11 & 4.50 & 5.10 & 2.90 & 1.40 & 24.83 \\
\hline 12 & 4.15 & 4.71 & 2.75 & 1.20 & 19.22 \\
\hline 13 & 3.90 & 4.62 & 2.62 & 1.15 & 17.40 \\
\hline 14 & 3.85 & 4.81 & 2.51 & 1.10 & 19.26 \\
\hline 15 & 4.21 & 4.90 & 2.65 & 1.25 & 22.28 \\
\hline 16 & 4.60 & 4.90 & 2.70 & 1.15 & 25.92 \\
\hline 17 & 3.65 & 4.41 & 2.60 & 1.10 & 14.13 \\
\hline 18 & 3.85 & 4.61 & 2.71 & 1.00 & 16.46 \\
\hline 19 & 4.20 & 4.82 & 2.80 & 1.20 & 20.26 \\
\hline 20 & 3.95 & 4.30 & 2.75 & 1.15 & 14.26 \\
\hline 21 & 4.36 & 4.61 & 2.80 & 1.28 & 19.54 \\
\hline 22 & 4.10 & 4.55 & 2.61 & 1.10 & 18.58 \\
\hline 23 & 4.40 & 4.71 & 2.65 & 1.20 & 22.33 \\
\hline 24 & 4.51 & 4.75 & 2.71 & 1.25 & 21.77 \\
\hline 25 & 4.40 & 4.92 & 2.80 & 1.30 & 22.99 \\
\hline Minimum & 3.57 & 4.15 & 2.41 & 0.95 & 14.13 \\
\hline maximum & 4.70 & 5.10 & 2.90 & 1.40 & 30.67 \\
\hline mean & 4.10 & 4.66 & 2.67 & 1.17 & 19.58 \\
\hline S.D. & 0.32 & 0.26 & 0.12 & 0.10 & 4.57 \\
\hline C.V. & 0.08 & 0.06 & 0.04 & 0.09 & 0.23 \\
\hline
\end{tabular}

S.D. $=$ Standard deviation

C.V. $=$ Coefficient of variation

$\mathrm{PS}_{\mathrm{cv}}=$ Canopy volume, $\mathrm{m}^{3}$

$\mathrm{D}_{1} \quad=\quad$ Canopy diameter parallel to the row $(\mathrm{m})$

$\mathrm{H}_{\mathrm{t}} \quad=\quad$ Overall canopy height above ground level, $\mathrm{m}$

$\mathrm{H}_{\mathrm{c}} \quad=\quad$ Height at maximum canopy diameter, $\mathrm{m}$

$\mathrm{H}_{\mathrm{s}}=$ Height from ground to canopy skirt, 
Table.2 CRD ANOVA of performance of Centrifugal Blower for different Parameters

\begin{tabular}{|l|l|l|l|l|}
\hline SN & Parameters & Treatment & Error & P \\
\hline & df & {$[3]$} & {$[8]$} & \\
\hline $\mathbf{1}$ & Mean air velocity, $\mathrm{m} / \mathrm{s}$ & $398.52127 * *$ & 0.27495 & 0.000 \\
\hline $\mathbf{2}$ & Air discharge, $\mathrm{m}^{3} / \mathrm{s}$ & $0.2466 *$ & 0.03515 & 0.013 \\
\hline $\mathbf{3}$ & Dynamic pressure, $\mathrm{N} / \mathrm{m}^{2}$ & $111858.54 * *$ & 0.434125 & 0.000 \\
\hline $\mathbf{4}$ & Static pressure, $\mathrm{N} / \mathrm{m}^{2}$ & $264.64927 * *$ & 0.086175 & 0.000 \\
\hline $\mathbf{5}$ & Total pressure, $\mathrm{N} / \mathrm{m}^{2}$ & $101983.99 * *$ & 0.2539583 & 0.000 \\
\hline $\mathbf{6}$ & Input power to blower, $\mathrm{kW}$ & $1.5049 * *$ & 0.0872833 & 0.001 \\
\hline $\mathbf{7}$ & Output power of blower, $\mathrm{kW}$ & $2.401675 * *$ & 0.002325 & 0.000 \\
\hline $\mathbf{8}$ & Efficiency of blower, \% & $45.370475 * *$ & 0.00125 & 0.000 \\
\hline $\mathbf{9}$ & Spray throw, $\mathrm{m}$ & $13.6875 * *$ & 0.0325 & 0.000 \\
\hline
\end{tabular}

* Significant at 5 per cent and ** Significant at 1 per cent

Table.3 Performance of Centrifugal Blower at different blower speeds

\begin{tabular}{|c|c|c|c|c|c|}
\hline \multirow[t]{2}{*}{ Sr. No. } & \multirow[t]{2}{*}{ Parameters } & \multicolumn{4}{|c|}{ Blower speed in rpm $(\mathbf{N})$} \\
\hline & & 1800 & 2000 & 2200 & 2400 \\
\hline 1 & Mean air velocity, $\mathrm{m} / \mathrm{s}$ & 84.34 & 88.31 & 104.51 & 107.45 \\
\hline 2 & Air discharge, $\mathrm{m}^{3} / \mathrm{s}$ & 2.16 & 2.25 & 2.66 & 2.73 \\
\hline 3 & Dynamic pressure, $\mathrm{N} / \mathrm{m}^{2}$ & 1244.90 & 1350.84 & 1534.28 & 1679.96 \\
\hline 4 & Static pressure, $N / \mathrm{m}^{2}$ & 78.48 & 68.67 & 58.86 & 58.86 \\
\hline 5 & Total pressure, $\mathrm{N} / \mathrm{m}^{2}$ & 1323.37 & 1419.51 & 1593.14 & 1738.82 \\
\hline 6 & Input to blower, $\mathrm{kW}$ & 3.35 & 3.71 & 4.54 & 5.54 \\
\hline 7 & Output of blower, kW & 2.84 & 3.19 & 4.24 & 4.76 \\
\hline 8 & Efficiency of blower, \% & 84.84 & 86.03 & 93.26 & 85.78 \\
\hline 9 & Horizontal spray throw, m & 11.00 & 12.50 & 14.00 & 16.00 \\
\hline
\end{tabular}

Fig.1 Measurement of canopy height and other tree parameters in HDP mango orchard

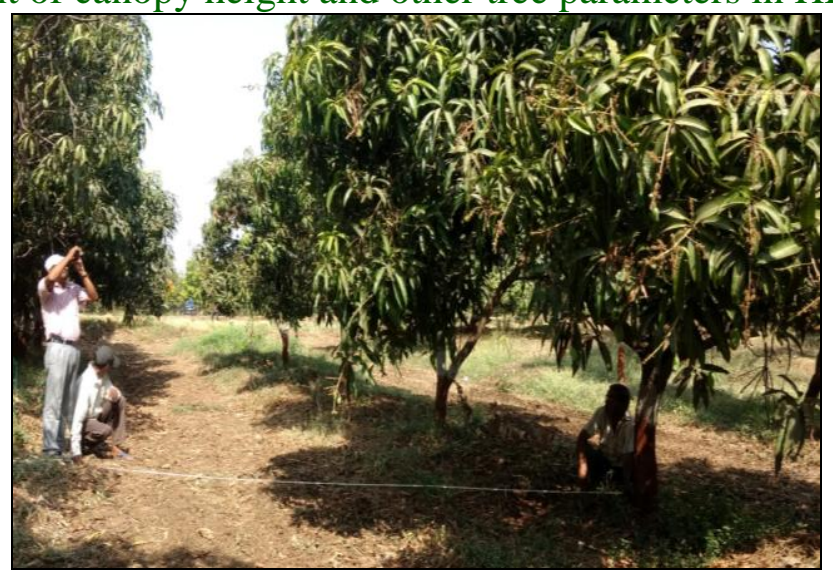


Fig.2 Schematic diagram of developed impeller of centrifugal blower

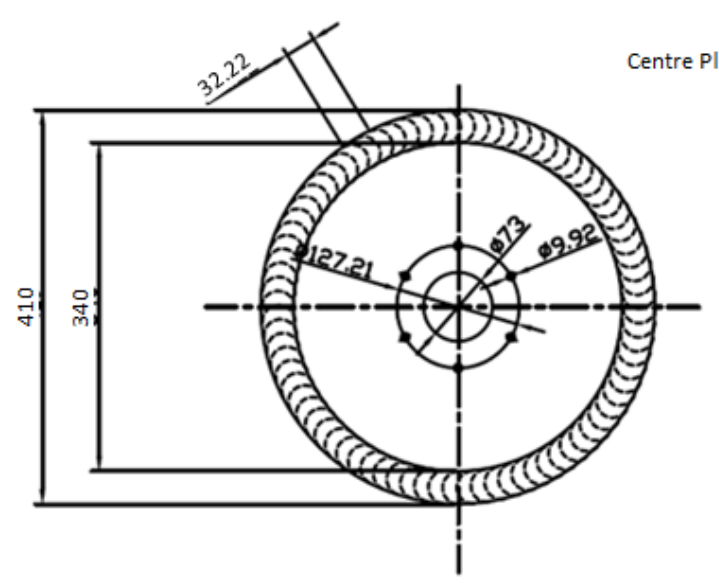

ELEVATION

Side Plate of $0.914 \mathrm{~mm}$ thickness

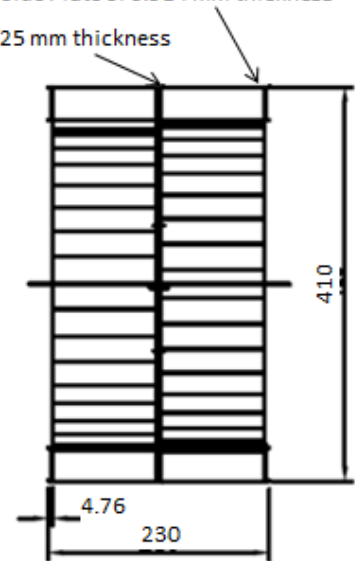

SIDE VIEW

ALL DIMENSIONS ARE IN MM NO OF BLADE $=40$

BLADE THICKNESS $=16$ SWG $=1.62 \mathrm{MM}$

Fig.3 Developed impeller

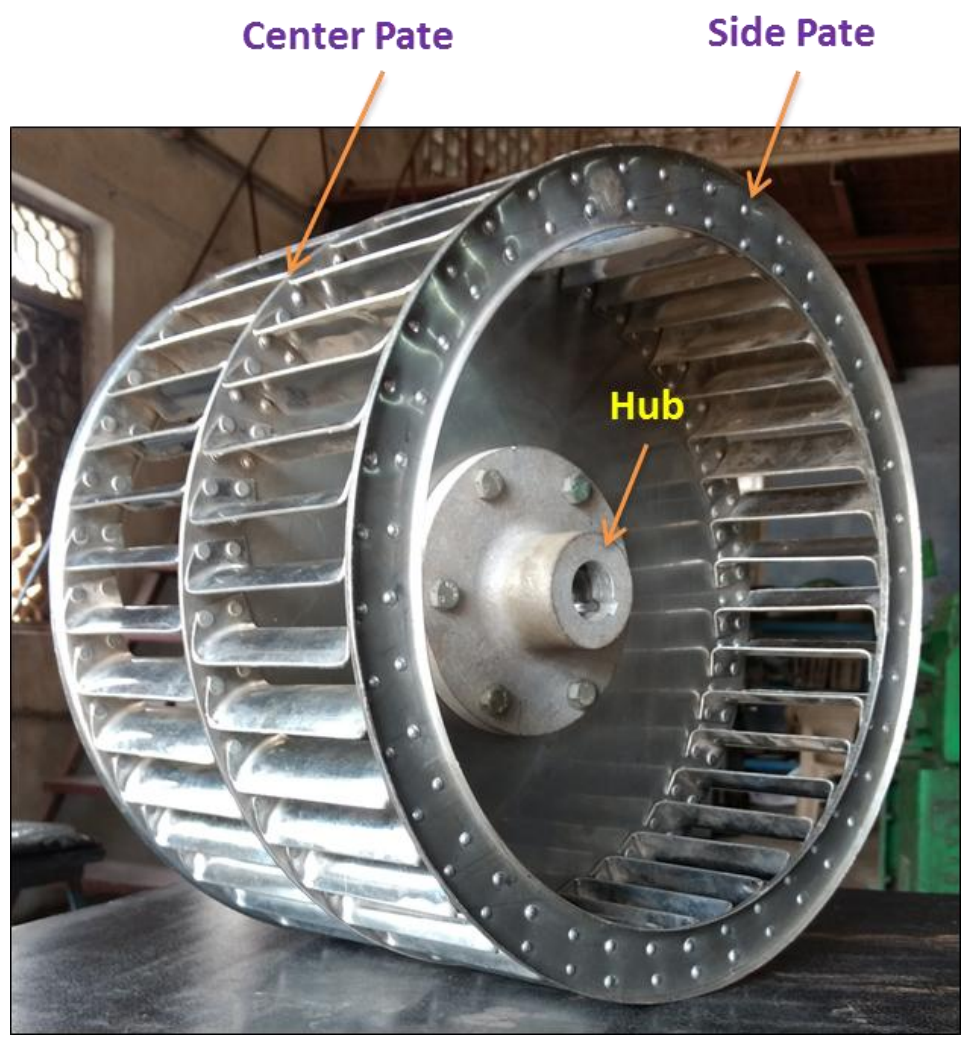


Fig.4 The schematic diagram of blower casing

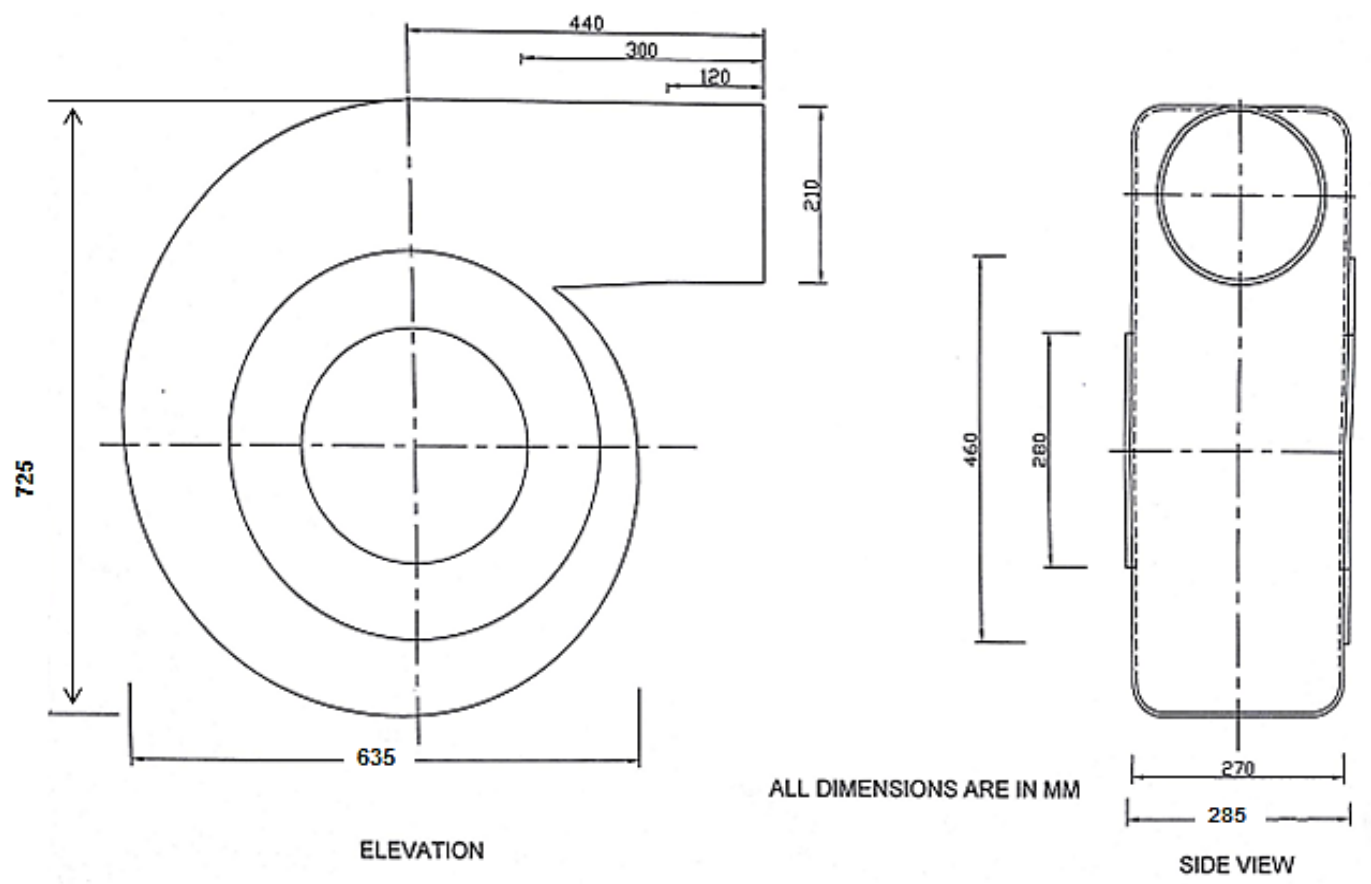

Fig.5 The developed blower casing

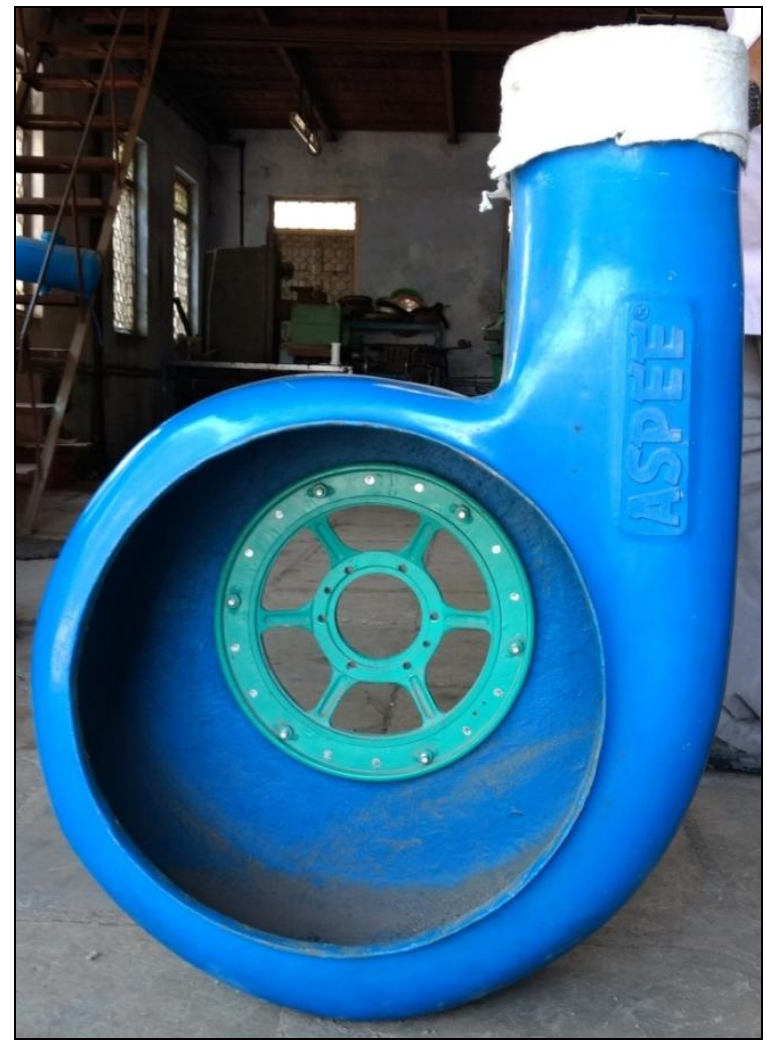


Fig.6 Complete set up for testing the performance of the centrifugal blower

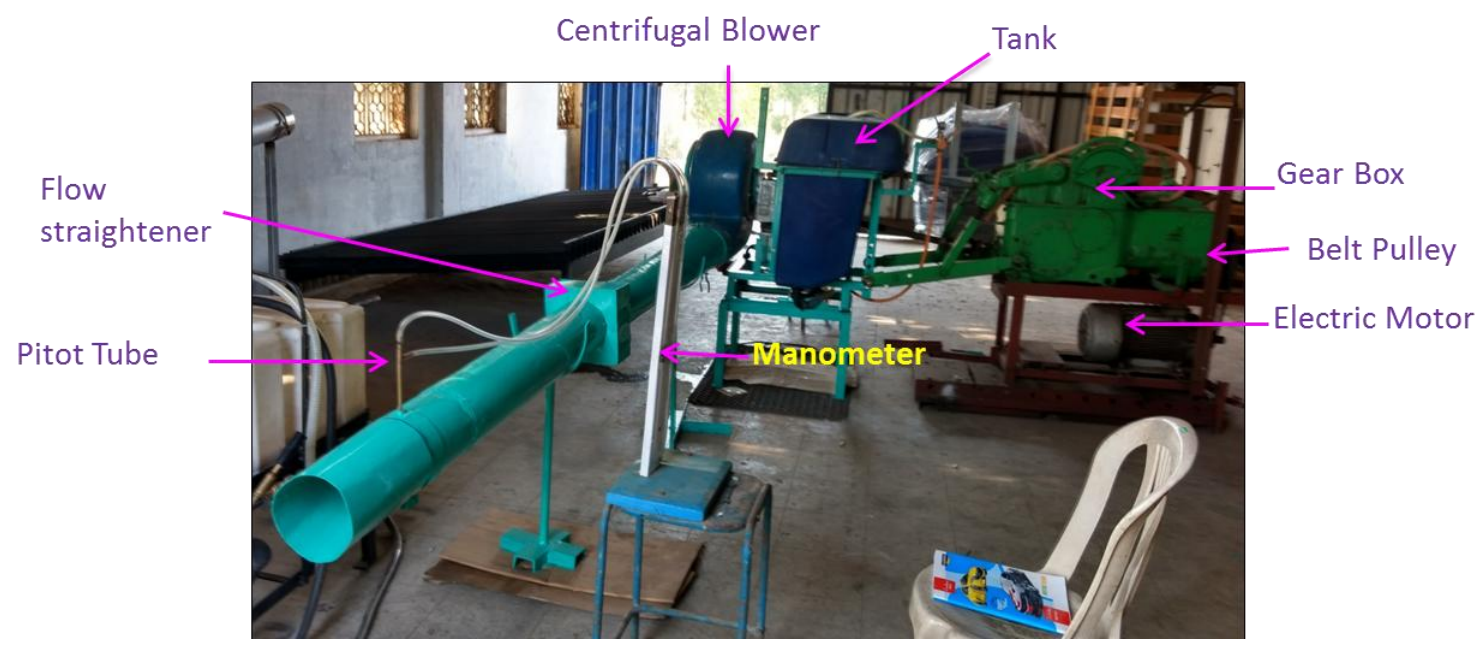

Fig.1 Effect of blower speed on air discharge output of blower

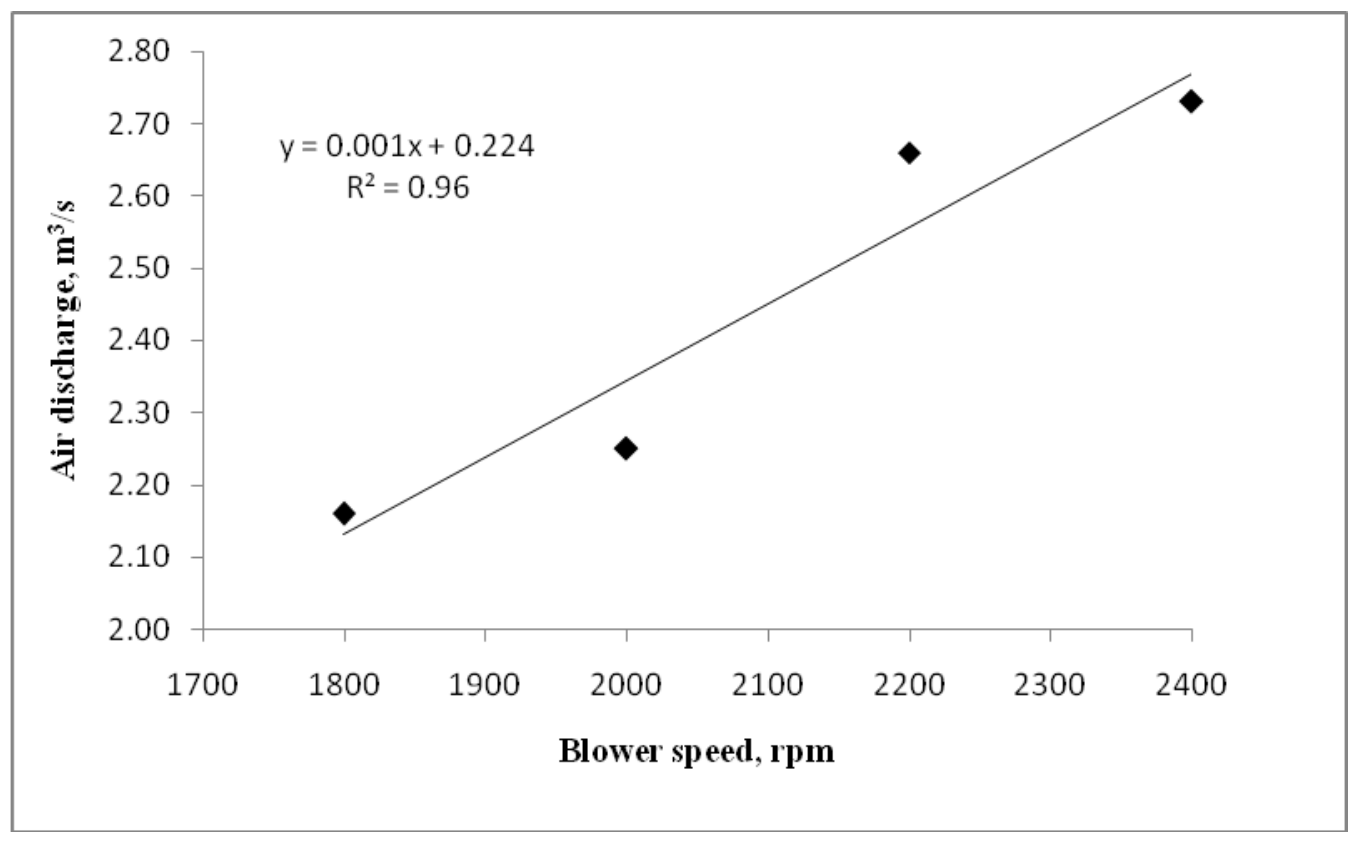

Effect of blower speed on blower efficiency and horizontal spray throw

The performance parameters of developed blower like blower efficiency and horizontal spray throw was calculated at all four levels of blower speeds and are given in table 3 . The data were analyzed statistically and reported in table 2. ANOVA ( table 2 ) shows that the blower speed had a significant effect on blower efficiency and horizontal spray throw at 1 per cent level of significance. The results obtained ( table 2 ) shows that maximum blower efficiency of 93.26 per cent was found at $2200 \mathrm{rpm}$ and minimum of 84.48 per cent was at $1800 \mathrm{rpm}$. The blower speed increased 
from $1800 \mathrm{rpm}$ to $2200 \mathrm{rpm}$, the efficiency of blower increased and thereafter decreased with increase of blower speed and it was 85.78 per cent at $2400 \mathrm{rpm}$. This effect observed may be due to decrease in the static pressure at the casing tongue as air discharge increased. Also the results obtained reveals that the spray throw varied from $11.00 \mathrm{~m}$ at $1800 \mathrm{rpm}$ to $16.00 \mathrm{~m}$ at $2400 \mathrm{rpm}$. and spray throw increases with increase in speed of blower. Similar results were obtained by Vibhakar (2012) and Dhande (2014).

\section{Effect of blower speed on input power and total pressure of the blower}

The developed centrifugal blower was operated at four speeds (1800, 2000, 2200, $2400 \mathrm{rpm}$ ) and data were collected for input power and total pressure and given in table 3 . The data were analyzed statistically. Table 2 shows that blower speed has significant effect on the input power and total air pressure had a significant effect at 1 per cent level of significance. The input power and total air pressure of blower are increased with increase in blower speed.

The table 3 shows that that the desired air discharge of $2.66 \mathrm{~m}^{3} / \mathrm{s}$ was found at $2200 \mathrm{rpm}$ whereas theoretical requirement was 2.50 $\mathrm{m}^{3} / \mathrm{s}$ for efficient spraying operation in HDP mango orchard. Furthermore the table also shows that the maximum blower efficiency of 93.26 per cent and the sufficient horizontal spray throw was found at $2200 \mathrm{rpm}$ blower speed.

On the basis of research carried out and result obtained the following conclusion were drawn.

1. Air volume requirement of aero blast sprayer for HDP mango orchard was found $2.5 \mathrm{~m}^{3} / \mathrm{s}$.

2. The best performance of design and developed centrifugal blower was found at $2200 \mathrm{rpm}$ with air velocity $104.51 \mathrm{~m} / \mathrm{s}$, air discharge $2.66 \mathrm{~m}^{3} / \mathrm{s}$, blower input power $4.54 \mathrm{~kW}$ and blower efficiency $93.26 \%$.

\section{References}

Adachi, T., Sugota, N. and Yamada, Y. 2001. Study on the Performance of a Sirocco Fan (Optimum Design of Blade Shape). International Journal of Rotating Machinery 7 : 405-414.

Anonymous. 2013. Indian Horticulture Database 2013. NHB, New Delhi. Paper No. AA 91-005.

Dhande, K. G. 2014. Design and development of centrifugal blower and rotary atomizer of air-assisted sprayer for Mango orchard. Unpublished Ph.D Thesis. MPUAT Udaipur (India)

Fox, R.D., Derksen, R.C., Zhu, H., Brazee, R.D. and Svensson, S.A. 2008. A history of Air blast sprayer: Development and future prospects. Trans. of the ASABE 51 : 405-410.

Joseph, M. B. 1990. Calibration of mist blower. Applied Technology Course, Hardi Publications, Leida Spain: 1-4.

Pompe, J. C. A. M. and Holterman, H. J. 1992. Technical aspects of pesticide application Wageningen Agriculture University.

Reddy, B.M.C. 2004. High density planting in horticultural crops. First Indian Horticulture Congress, $\quad 6^{\text {th }}-9^{\text {th }}$ November, New Delhi p. 36.

Vibhakar, N.N., Masutage and Channiwala, S.A. 2012. Three dimensional CFD Analysis of backward curved radial tipped Centrifugal Fan designed as per unified methodology with varying number of blades. Int.J. of emerging trends in engg. and development. 2(1):246-256.

Wilson and Irons. 1962. The swath pattern of 
tomato disease control with air blast sprayers. The Ohio Agricultural
Experiments Research Station. Circular No.77.

\section{How to cite this article:}

Badgire, B. B., S. M. Mathur, R. K. Rathod and Tiwari, G. S. 2020. Laboratory Performance of Developed Centrifugal Blower of Aero Blast Sprayer for High Density Plantation Mango Orchard. Int.J.Curr.Microbiol.App.Sci. 9(01): 1537-1548.

doi: https://doi.org/10.20546/ijcmas.2020.901.171 